\title{
La experiencia madrileña de Neruda: su evolución ideológica, el cambio de estética y su compromiso frente a España ${ }^{1}$
}

\author{
José MANUel LóPez De ABiada \\ Universidad Politécnica Federal de Zurich (Suiza)
}

\section{Acotaciones previas}

Quien consulte los índices de nombres propios y geográficos que aparecen al final de cada tomo de las Obras completas de Neruda ${ }^{2}$, advertirá en seguida, quizá con sorpresa, que el término España va seguido, en ambos libros, de muchas cifras. Notará también que éstas (que

1 Este trabajo fue presentado, con leves cambios, en el Ateneo Popular Español de Zurich, en el marco de un ciclo de conferencias (septiembre-noviembre de 1978) destinadas a conmemorar el quinto aniversario de la muerte del poeta. En ese ciclo, que llevaba por título La experiencia madrileña de Neruda, su cambio de estética y su relación con España, di también dos ponencias sobre Caballo verde para la Poesía, recogidas después en un amplio trabajo titulado «De la polémica fortuita e improcedente al mito literario. Notas y aclaraciones sobre Caballo verde para la poesía» (Cuadernos hispanoamericanos, n. ${ }^{\circ} 430,1986$. pp. 141-163). Estos ensayos deberían haber aparecido, en forma de libro, con otros trabajos sobre algunos novelistas y poetas del 27. Sin embargo, como el proyectado libro todavía está lejos de ser concluido, publico este trabajo por separado, en ocasión de los ochenta años del nacimiento de Pablo Neruda.

2 Me refiero a la edición de Losada, Buenos Aires, 1968, I-II, págs. 1551-1563 y 1613-1627. 
corresponden, evidentemente, a las páginas en las que aparece, una o más veces, el nombre propio España) ocupan incluso más espacio que las referidas a otros lugares íntimamente ligados a la biografía de Neruda. Es más, el único topónimo que aparece, en ambos volúmenes, seguido de más cifras que España es Chile. América acapara más números que España sólo en el primer tomo. Isla Negra, Valparaíso, Santiago de Chile, Europa, etc., surgen con menor frecuencia que España. Ése parece ser también el caso en las memorias (Confieso que he vivido, Barcelona, Seix Barral, 1974) y en las prosas reunidas por Matilde Neruda y Miguel Otero Silva (Para nacer he nacido, Barcelona, Seix Barral, 1978): Neruda se refiere, en ambas obras, a España y a temas españoles con mucha frecuencia.

Quien, tras estas constataciones, desee profundizar en la materia, constatará asimismo que en la ingente bibliografía sobre la obra nerudiana faltan, precisamente, estudios al respecto. Es más, que yo sepa, carecemos incluso de un puntual y abarcador trabajo que examine la evolución de la poesía de Neruda durante su estancia en España (1934-36), evolución que, como sabemos, fue significativa y esencial. Tampoco contamos con un estudio riguroso sobre la revista Caballo verde para la poesía (dirigida, como es sabido, por Neruda), pese a su importancia, y a las sugerencias y recomendaciones de algunos de los mejores conocedores de la revista ${ }^{3}$.

\section{Caballo verde para la poesía}

De una lectura atenta de los cuatro números de Caballo verde para la poesía (aparecidos entre octubre de 1935 y enero de 1936) se desprende con nitidez que en la revista, además de coincidir poetas consagrados, noveles y desconocidos, están representadas corrientes ideológicas y estéticas disímiles e incluso opuestas. Es más: sólo los poemas de Serrano Plaja, González Tuñón y, en parte, Alberti pueden ser considerados, en cierto modo, representantes de una poesía sin pureza, aunque más en el sentido de poesía comprometida o militante que en la acep-

3 Cfr., por ejemplo, Juan Cano Ballesta, La poesía española entre pureza y revolución, Madrid, Gredos, págs. 200-214 y la introducción de Jan Lechner a la edición facsímil de Caballo verde para la Poesia, Glashütten im Taunus, Verlag Detlev Anvermann, 1974. 
ción del tantas veces citado manifiesto nerudiano del primer número de la revista. Porque sucede que en el sintagma nerudiano no había lugar para la poesía militante o, menos aún, revolucionaria: en el programa poético del manifiesto «Sobre una poesía sin pureza» quedaba claramente formulado que el poeta no debía «aceptar deliberadamente nada». De ahí que, de los treinta y dos poemas aparecidos en los cuatro números de la revista, sólo los dos de Serrano Plaja y el de González Tuñón merezcan el calificativo de impuros. Los de Alberti son ejemplos evidentes de poesía militante, con excepción del soneto dedicado a la memoria de Sánchez Mejías, que es, evidentemente, elegíaco. Si además consideramos que la revista publicaba sólo poemas (la mayoría incluso de signo intimista, herméticos; algunos son inclusive de claro cuño purista), que de los veintiocho poetas que colaboraron sólo los nombres de Alberti y Serrano Plaja aparecen en más de un número, que entre los colaboradores había, además de los españoles, cuatro argentinos, tres chilenos, dos franceses y un alemán, y que tanto las edades como las preferencias literarias e ideológicas de los colaboradores diferían entre sí, podemos deducir que Caballo verde para la poesía era una revista de tamaño reducido, destinada a la inmensa minoría ${ }^{4}$. En fin, el análisis de los cuatro breves textos en prosa que preceden a los poemas de cada número lleva a la conclusión siguiente: los famosos textos nerudianos carecen de una teoría poética coherente y precisa. Es por tanto sorprendente que la crítica haya venido afirmando que Caballo verde contribuyó decisivamente en el proceso de rehumanización de la literatura española de preguerra. Se trata de un tópico desatinado: ese proceso había comenzado hacia 1928, en el reducido grupo de Edicio-

4 Caballo verde para la poesía se vendía sólo en algunas librerías madrileñas, al precio de 2'50 pesetas. Octubre (1933-34), por ejemplo, costaba 50 céntimos. Nueva España (1930-31), la revista de avanzada más importante de su época (alcanzó una tirada de 40.000 ejemplares en el núm. 2) se vendía en quioscos y librerías y se enviaba a los abonados; el precio del ejemplar era de 35 céntimos. Revista de Occidente y Cruz y Raya costaban, respectivamente, 3'50 y 3 pesetas. En cuanto a la distribución de Caballo verde es quizá ilustrador un pasaje aparecido en el número 4 de Hoja literaria, de Barcelona: «Afirmamos no conocer al Caballo Verde para la Poesía, recientemente aparecido en Madrid. Y no lo conocemos porque aún no ha llegado a Barcelona. Dos meses - apareció en octubre - es mucho tiempo para no haber cubierto, aun a paso de burro cojitranco, la distancia que media entre Madrid y Barcelona. ¿Es que se trata de un caballo de ruedo taurino que para que atraiga la querencia del toro ha sido pintado de verde?». Citado por Ricardo Gullón en la nota 2 de su esclarecedor trabajo «Relaciones Pablo Neruda - Juan Ramón Jiménez», en Hispanic Review, núm. 39, abril de 1971, págs. 141-166. Aquí pág. 148. 
nes Oriente (nótese el segundo sustantivo, en neta oposición al Occidente de la revista orteguiana), capitaneado por José Díaz Fernández, José Antonio Balbontín, Joaquín Arderíus, José Venegas y Rafael Giménez Siles ${ }^{5}$. Los editoriales de Neruda respondian más a la descripción de su propia poesía y a sus dicterios contra Juan Ramón y sus seguidores que a la formulación de una teoría poética concreta ${ }^{6}$. ¿Tienen estas constataciones una relación con el pasaje que a continuación transcribo? Podría ser:

A Rafael Alberti no le gustó el título:

- ¿Por qué va a ser verde el caballo? Caballo Rojo debería llamarse.

No le cambié el color. Pero Rafael y yo no nos peleamos por eso. Nunca nos peleamos por nada. Hay bastante sitio en el mundo para caballos y poetas de todos los colores del arco iris ?

\section{Neruda y España}

Entre los numerosos textos nerudianos que podríamos citar para ejemplificar su amor por España y lo vinculado que se sentía a lo español, cabe acaso recordar la carta a los poetas españoles que Neruda en-

5 Me permito señalar, a posteriori, algunos trabajos míos al respecto: José Díaz Fernández: narrador, critico, periodista y político, Bellinzona, Casagrande, 1980; «Semblanza de José Venegas, hombre clave en la promoción y difusión de la cultura durante el quinquenio 1927-32», en Revista de historia moderna y contemporánea, 8, noviembre de 1981, págs. 29-42; «José Díaz Fernández: la superación del vanguardismo», en Los Cuadernos del Norte, 11, enero-febrero de 1982, págs. 56-65; «Acercamiento al grupo editorial de Post-Guerra (1927-28)», en Iberoromania (Tübingen), 17 N.F. (1983), págs. 42-65; «La Venus mecánica: de la literatura de vanguardia a la literatura de avanzada», en José Diaz Fernández, La Venus mecánica, Introducción, edición y notas de José Manuel López de Abiada, Barcelona, Laia, 1983, págs. 5-30; José Antonio Balbontín, Antología poética (1910-1975), Edición y prólogo de José Manuel López de Abiada, Madrid, José Esteban Editor, 1983; «De la vanguardia deshumanizada al nuevo realismo. Notas sobre El nuevo romanticismo y la novela española (1923-1932)»), en Versants (Fribourg), 5 (1983), págs. 139-154; «De escritores silenciados y manuales de literatura: en torno a los novelistas marginados de la generación del 27 », en De los romances-villancico a la poesía de Claudio Rodríguez. 22 ensayos sobre las literaturas española e hispanoamericana en homenaje a Gustav Siebenmann, Edición de José Manuel López de Abiada y Augusta López Bernasocchi, Madrid, José Esteban Editor, 1984, págs. 213-252.

6 Para más detalles, cfr. el trabajo indicado en la nota 1 («De la polémica fortuita e improcedente al mito literario»).

7 Pablo Neruda, Confieso que he vivido. Memorias, Barcelona, Seix Barral, 1980, págs. 169. 

chada el 27 de septiembre de 1957, escribe Neruda:

Queridos poetas españoles, aquí me tienen muy cerca de la tierra española y lleno de sufrimientos por no verla y tocarla. Soy un desterrado especial, vivo soñando con España, con la grande y la mínima, la del mapa y la de las callejuelas, soñando con todo el amor que entre vosotros dejé, un desterrado que sólo puede acercarse al aire que perdió. Cuántas veces, de noche, el avión que me conducía lejos sobrevoló vuestra tierra, y yo, acongojado, traté de descifrar las luces que, como luciérnagas, brillaban allá abajo. Eran casas perdidas, pueblos sumergidos, montes oscuros, $y$, tal vez, rostros amados que no volveré a ver. Mi corazón, allí arriba, volando sintió de nuevo la tierra magnética y se llenó de lágrimas. Poetas españoles, nos ha separado un frío cruel y años pasados como siglos. Nosotros, poetas americanos, queremos renovar la fraternidad y la continuidad de nuestra paralela poesía. Hemos sido separados por errores propios y ajenos, por profundos dolores, por un silencio imposible. La poesía debe volver a unirnos. La poesía debe reconstruir los vínculos rotos, reestablecer la amistad y elevar universalmente nuestro canto. Tal es nuestra tarea. A ella me daré entre mis pueblos. Vosotros diréis vuestra palabra. Y habremos dado así el primer paso, que no por tardío será menos fecundo. Va en este papel mi afecto fraternal y mi confianza en la poesía y en el honor de los poetas.

En otra entrevista posterior con Antonio Colinas, Neruda vuelve a hablar de su relación con España, y se muestra dolido por el hecho de que algunos poetas españoles le hubiesen tildado de antiespañol (alude principalmente a las acusaciones de Panero ${ }^{9}$, Ridruejo y Rosales):

¿Qué puedo yo decir de España, de sus hombres, de sus tierras? España es una parte muy importante en mi vida: una parte extraordinariamente grave, profunda y decisiva en mi historia personal. Y uno de los reproches - de los

8 Cfr. «Inédito de Neruda. Carta a los poetas españoles», en Triunfo, núm. 580 (10 de noviembre de 1973), pág. 25. En la presentación del inédito nerudiano, apunta Figuera Aymerich: «Estando yo [Ángela Figuera] en París, en diciembre de 1957, conocí a Neruda. Hablamos mucho. De España, de poesía, de los poetas españoles. De España sobre todo. Con su voz grave y lenta, como una miel que cayera gota a gota, me habló Pablo Neruda del amor que siempre habia sentido por España y por sus hermanos los poetas españoles. Pero un dolor terco, tan profundo como su amor, lo mantenía entonces, física y espiritualmente, alejado de ella, vuelto de espaldas, sordo y mudo a todo lo que de España procediera. Hablamos mucho. Le hice saber muchas cosas. Discutimos de los poetas españoles: los de siempre, los de antes y los del momento. Le conmovió al fin. El amor se impuso, y al despedirnos me entregó una carta dirigida a los poetas españoles, una carta generosa y bella para todos sus amigos de España, una verdadera carta de amor que todo español puede leer como si fuera su destinatario». Panero, Antología, Barcelona, Plaza \& Janés, 1973, págs. 107-120. Selección, prólogo y notas de Juan Luis Panero. 
muchos reproches [...] - es que me llamen antiespañol. Esta es una confusión lamentable. Una cosa es lo que yo siento por España, por sus hombres y por sus tierras y otra cosa es lo que siento por algunos matices de la vida y de la historia de España. Eso es otra cosa. A lo largo de toda la historia de España - como a lo largo de la historia de todas las naciones sin excepciónhay partes que son predilectas y hay partes que son desagradables. Esto es algo que sentirán los mismos españoles. Y naturalmente en la historia de los hombres existe natural, individual y nacionalmente tal discriminación. Pero mi apego, y mi comprensión, y mi amor hacia España es para mí una cosa absolutamente indiscutible. Por eso me molesta que me reprochen lo contrario ${ }^{10}$.

Sobre la importancia de la poesía de Neruda para los poetas españoles de la posguerra, baste recordar que la revista leonesa Espadaña " publicó, en la sección «Poesía y vida. Textos no clásicos» (nótese la ironía) del número 30 (1947), algunos fragmentos del Canto general, correspondientes a las «Alturas de Macchu Picchu», precedidos incluso de unas claramente comprometida prosa nerudiana de 1936. Pero ya antes de 1947, un poema de Neruda había aparecido, abanderándolo, en un poemario clandestino editado en España durante el franquismo. Me refiero a Pueblo cautivo, publicado anónimo en 1946, pero debido a la pluma de uno de los poetas jóvenes más comprometidos de la época, Eugenio de Nora ${ }^{12}$. El poema que abría el libro clandestino era «Explico algunas cosas» y pertenecía, significativamente, a España en el corazón (1936-37) ${ }^{13}$.

Obviamente, no pretendo presentar ahora un recuento minucioso y preciso de los poemas nerudianos que tratan de España o se refieren a sus amigos españoles o a su estancia madrileña, pues sabido es que, desde la segunda Residencia en la tierra (1931-35), en todos sus libros hay referencias a España. Me limitaré en este apartado a señalar algu-

10 Antonio Colinas: «Entrevista con Pablo Neruda», en Revista de Occidente, núm. 111, abril-junio de 1972, págs. 255-266; aquí págs. 261-262.

1 Cfr. la edición facsímil de Espadaña, León, Espadaña Editorial, 1978, págs. 637-639.

12 Sobre la autoría de Pueblo cautivo, cfr. mi trabajo «Observaciones en torno a la poesía de posguerra. Conversación con Eugenio de Nora», en Insula, núm. 407, octubre de 1980, págs. 3-4. De Pueblo cautivo existe una edición accesible en Ediciones Peralta, Madrid, 1978, con prólogo de Fanny Rubio.

13 Sobre la presencia de la poesía de Neruda en la poesia española de posguerra, cfr. Charles David Ley: «Influencia de Pablo Neruda y de otros poetas hispanoamericanos en la moderna poesía de España», en Carlos H. Magis (ed.), Actas del tercer congreso internacional de hispanistas, México, El Colegio de México, 1970, págs. 543-552. 
nos de los momentos más significativos posteriores a la sección IV de la tercera Residencia en la tierra («España en el corazón»). De alguno de los poemas de esa sección cuarta nos ocuparemos en el apartado correspondiente al cambio de estética.

$\mathrm{Si}$, como observa Loyola, en «España en el corazón» Neruda es «un testigo acusador que expone hechos, nombra criminales, relata, denuncia, que pide la atención de todos para el martirio español y que exige los castigos de la tierra y del infierno para los traidores» ${ }^{14}$, en el Canto general (1938-1949), al aspirar a narrar la historia ${ }^{15}$ de América, sus referencias a España cambian, ineludiblemente, de signo. Mas ello no significa que su actitud cambie, o, mucho menos, que desde entonces España aparezca exclusivamente con connotaciones negativas. Trata sencillamente de llamar a las cosas por su nombre: conquista significaba, en su opinión, entre otras muchas cosas (aunque no sólo eso), ocupación, violencia, incautamiento y despojo. Su papel de historiador, de cronista americano, implica, por tanto, una objetividad mayor que en la etapa anterior, de testigo acusador y luchador antifascista. España no es ahora la agredida, sino la agresora. Se trata, en definitiva, en algunos casos (especialmente en el libro III, «Los conquistadores»), de un mayor condicionamiento de la representación del yo poético, del hablante. Pero también hay, claro, momentos de gran personalismo y subjetividad, como podemos constatar, por ejemplo, en el poema «A $\mathrm{Mi}$ guel Hernández, asesinado en los presidios de España» ${ }^{16}$.

14 Hernán Loyola, Ser y morir en Pablo Neruda 1918-1945, Santiago de Chile, Editoria Santiago, 1967, pág. 171.

15 Recordemos que en Amor América (1400), el primer poema de Canto general, la quinta estrofa empieza con el verso: «Yo estoy aquí para cantar la historia» (I, pág. 319). En el ensayo «Algunas reflexiones improvisadas sobre mis trabajos», Neruda recurre incluso al lexema cronista: «Aunque muchas técnicas, desde las antiguas del clasicismo, hasta los versos populares, fueron empleadas por mí en este Canto, quiero algunas palabras sobre uno de mis propósitos. Se trata del prosaísmo que muchos me reprochan como si tal procedimiento manchara o empañara esta obra. Este prosaísmo está íntimamente ligado a mi concepto de CRÓNICA. El poeta debe ser, parcialmente, el CRONISTA de su época. La crónica no debe ser quintaesenciada, ni refinada, ni cultivista. Debe ser pedregosa, polvorienta, lluviosa y cotidiana. Debe tener la huella miserable de los días inútiles y las execraciones y lamentaciones del hombre» (II, pág. 1120).

16 «Que sepan los que te mataron que pagarán con sangre. / Que sepan los que te dieron tormento que me verán un día. / Que sepan los malditos que hoy incluyen tu nombre / en sus libros, los Dámasos, los Gerardos, los hijos / de perra, silenciosos 
En cuanto al binomio testigo acusador/España: algunos pasajes del poema «La guerra» (1936) (Libro XV, «Yo soy») son probablemente de los más ilustrativos ${ }^{17}$.

En "Vuelve España», su amor a España y su sufrimiento por la forzada ausencia son manifiestos ${ }^{18}$. El dolor de la ausencia de España, de un acaso definitivo alejamiento y privación de España, queda nítidamente reflejado en el poema «Si yo te recordara» (pág. 777). En fin, en «El fuego cruel», el tercer libro de Memorial de Isla Negra (1964), el tema de España surge de nuevo en varios poemas. Reproduzco sólo los versos más significativos:

\author{
¡Aquella guerra! El tiempo \\ un año y otro y otro \\ deja caer como si fueran tierra \\ para enterrar \\ aquello \\ que no quiere morir: claveles, \\ agua, \\ cielo, \\ la España, a cuya puerta \\ toqué, para que abrieran, \\ entonces, allá lejos. \\ Y alli llegué para cumplir mi canto ${ }^{19}$.
}

cómplices del verdugo, / que no será borrado tu martirio, y tu muerte / caerá sobre toda su luna de cobardes. / Y a los que te negaron en su laurel podrido, / en tierra americana, el espacio que cubres [...]». Libro XII (Los ríos del canto), I, pág. 635. Cito siempre por la edición indicada en la nota 2 . El lector recordará probablemente que las acusaciones de Panero y otros escritores y poetas españoles arriba aludidas tienen su origen principalmente en el Libro III de Canto general y en este poema a Miguel Hernández. En otro poema sobre Miguel Hernández, titulado «El pastor perdido", de Las uvas y el viento (1954), topamos con este pasaje referido a José María de Cossío: «Todos sabían, / en las cárceles, / mientras los carceleros / cenaban con Cossio, / tu nombre. / Era un fulgor mojado / por las lágrimas / tu voz de miel salvaje» (I, pág. 784).

17 I, pág. 702.

Las uvas y el viento, I, pp. 775-776.

19

En «El fuego cruel», poema que lleva el mismo título que el libro III de Memorial de Isla Negra, págs. 557-558.

El dolor de la ausencia queda asimismo reflejado, por ejemplo, en « $i$ Ay! Mi ciudad perdida»: «Me gustaba Madrid y ya no puedo / verlo, no más, ya nunca más, amarga / es la desesperada certidumbre / como de haberse muerto uno tambiẻn al tiempo / que morían los míos, como si se me hubiera / ido a la tumba la mitad del alma, / y allí yaciere entre llanuras secas, / prisiones y presidios, / aquel tiempo anterior 
En «Yo recuerdo», su antiguo cometido de testigo acusador se ha transformado en testimonio rememorador $y$ admonitor:

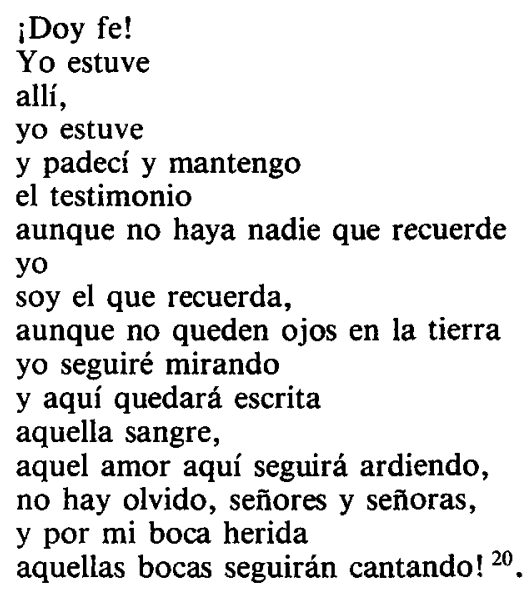

Testimonio rememorador y consciente de que la situación política en España, pese a los veintiséis años de dictadura, no parecía ofrecer esperanzas de cambio: el dolor se ha hecho a la paciencia, las esperanzas de los exiliados han ido decreciendo hasta esfumarse:

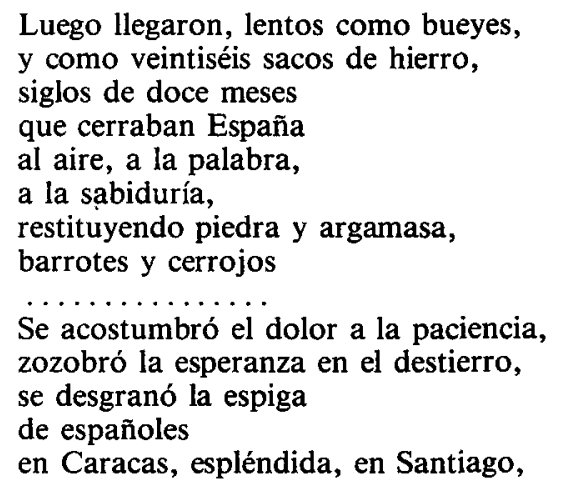

cuando aún no tenía / sangre la flor, coágulos la luna. / Me gustaba Madrid por arrabales, / por calles que caían a Castilla [...] / mientras enderezaba mi vaga dirección / hacia Cuatro Caminos, al número 3 / de la calle Wellintonia / en donde me esperaba / bajo dos ojos con chispas azules / la sonrisa que nunca he vuelto a ver / en el rostro / -plenilunio rosado - / de Vicente Aleixandre / que dejé allí a vivir con sus ausentes» (págs. 563-564).

II, págs. 559-560. 


\section{Evolución ideológica y cambio de estética}

La primera edición de «Las furias y las penas» (sección II de la Tercera residencia) apareció en la editorial Nascimiento de Santiago de Chile, en mayo de 1939. Se trataba de una separata de 29 páginas; la tirada era de sólo 120 ejemplares numerados. El epígrafe quevediano que encabezaba el poema iba precedido de la nota siguiente (recogida después también en las ediciones posteriores):

En 1934 fue escrito este poema. Cuántas cosas han sobrevenido desde entonces: España, donde lo escribí, es una cintura de ruinas. ¡Ay! Si con sólo una gota de poesía o de amor pudiéramos aplacar la ira del mundo, pero eso sólo lo pueden la lucha y el corazón resuelto.

El mundo ha cambiado y mi poesía ha cambiado. Una gota de sangre caída en estas líneas quedará viviendo sobre ellas, indeleble como el amor.

Marzo de $1939^{22}$.

En el poema «Tal vez cambié desde entonces», de Memorial de Isla Negra, Neruda hace también alusión expresa a la guerra civil española y a su evolución ideológica:

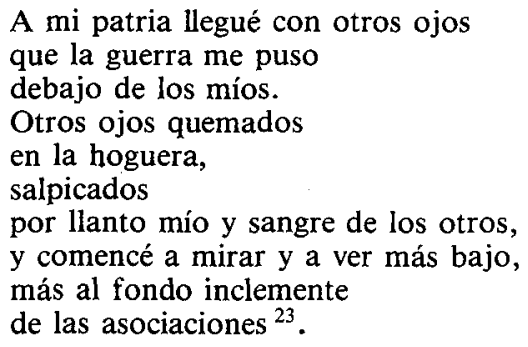

21 En «Mucho tiempo transcurre», II, pág. 560.

22 I, pág. 264. El subrayado es mío.

23 II, pág. 564. En sus memorias hay asimismo varios pasajes que corroboran estas afirmaciones. Cfr., p. ej., págs. 170 y 191 de Confieso que he vivido, op. cit. («Y de ese modo la guerra de España, que cambió mi poesía, comenzó para mí con la desaparición de un poeta»; «Aunque el carnet militante lo recibí mucho más tarde en Chile, cuando ingresé oficialmente al partido, creo haberme definido ante mí mismo como un comunista durante la guerra de España. Muchas cosas contribuyeron a mi profunda convicción»). 
Sin embargo, en la conferencia pronunciada en París, en febrero de 1937, sobre García Lorca, hallamos una aseveración sorprendente, quizá debida a una excesiva precaución y a circunstancias determinadas:

\begin{abstract}
He querido traer ante vosotros el recuerdo de nuestro gran camarada desaparecido. Muchos quizá esperaban de mí tranquilas palabras poéticas distanciadas de la tierra y de la guerra. La palabra misma España trae a mucha gente una inmensa angustia mezclada con una grave esperanza. Yo no he querido aumentar estas angustias ni turbar vuestras esperanzas, pero recién salido de España, yo, latinoamericano, español de raza y de lenguaje, no habría podido hablar sino de sus desgracias. No soy político ni he tomado nunca parte en la contienda política, y mis palabras, que muchos habrían deseado neutrales, han estado teñidas de pasión. Comprendedme y comprended que nosotros, los poetas de América española y los poetas de España, no olvidaremos ni perdonaremos nunca el asesinato de quien consideramos el más grande entre nosotros, el ángel de este momento de nuestra lengua. Y perdonadme que de todos los dolores de España os recuerde sólo la vida y la muerte de un poeta. Es que nosotros no podremos nunca olvidar este crimen, ni perdonarlo. No lo olvidaremos ni lo perdonaremos nunca. Nunca ${ }^{24}$.
\end{abstract}

Esta perentoria afirmación (me refiero a la frase «No soy político ni he tomado nunca parte en la contienda política») está en neto contraste con las declaraciones de los últimos párrafos de «Elegí un camino», donde explica las razones que le llevaron a optar por el comunismo ${ }^{25}$, mas sabido es que la obra nerudiana no está exenta de contradicciones ${ }^{26}$. Y sobre todo discrepa con su praxis poética de España en el corazón, cuyo primer poema publicado, «Canto a las madres de los milicianos muertos», apareció anónimo ${ }^{27}$ en el número 5 de El Mono

24 «Federico García Lorca», en Para nacer he nacido, op. cit., págs. 68-73. Aquí pág. 73. El subrayado es mío.

25 «Mientras esas bandas pululaban por la noche ciega de Madrid, los comunistas eran la única fuerza organizada que creaba un ejército para enfrentarlo a los italianos, a los alemanes, a los moros y a los falangistas. Y eran, al mismo tiempo, la fuerza moral que mantenía la resistencia y la lucha antifascista. Sencillamente: había que elegir un camino. Eso fue lo que yo hice en aquellos días y nunca he tenido que arrepentirme de una decisión tomada entre las tinieblas y la esperanza de aquella época trágica» (Confieso que he vivido, op. cit., págs. 192-193).

26 Cito un único ejemplo, en clara discrepancia con las afirmaciones arriba reproducidas (nota 15): «En cuanto al realismo debo decir, porque no me conviene hacerlo, que detesto el realismo cuando se trata de la poesía. Es más, la poesía no tiene por qué ser sobrerrealista o subrealista, pero puede ser antirrealista. Esto último con toda la razón, con toda la sinrazón, es decir, con toda la poesía) (Confieso que he vivido, op. cit., pág. 401).

27 El poema fue publicado anónimo a petición del propio Neruda, entonces todavía diplomático, aunque precedido de la nota siguiente: «Este poema se debe a la plu- 
Azul, la revista de guerra que publicaba la Alianza de Intelectuales Antifascistas y dirigían Alberti y María Teresa León. Se trata de su primer poema políticamente comprometido. El segundo poema que publicó en El Mono Azul ya iba firmado, puesto que, entre tanto, había sido destituido, por su actividad política, de su cargo de diplomático, y se hallaba en Francia, defendiendo públicamente la causa republicana: daba conferencias; editaba y componía, a mano, en la imprenta de la casa de campo de la exaristócrata inglesa Nancy Cunard, la revista Los poetas del mundo defienden al pueblo español; fundó, con César Vallejo, en abril de 1937, el Grupo Hispanoamericano de Ayuda a España; integraba el grupo editor del boletín semanal Nuestra España; asistió al Congreso de las Naciones Americanas, donde presentó una ponencia sobre el influjo de España y Francia en las literaturas lationamericanas; asistió al II Congreso Internacional de Escritores Antifascistas, que se celebró, en julio de 1937, en Barcelona, Valencia, Madrid y París ${ }^{28}$; fundó y presidió, tras su regreso a Chile (octubre del 37), la Alianza de Intelectuales de Chile para la Defensa de la Cultura. El segundo poema aparecido en el número 22 de El Mono Azul (1. ${ }^{\circ}$ de julio de 1937) se titulaba «Es así», luego integrado, con algunas variantes y supresiones, en España en el corazón, con el título de «Explico algunas cosas». En este poema se encuentran, precisamente, los principales componentes de la nueva poética nerudiana. Veamos brevemente cuáles son. Pero antes es acaso oportuno señalar los pasajes suprimidos y algunas variantes de «Es así» con relación a la versión definitiva de las Obras completas, ya que en ellas encontramos algunos elementos significativos.

En la versión definitiva desaparecen la estrofa «Asesinos de pueblos pobres, asesinos de niños, / asesinos de casas pobres y cercados, / asesinos de madres ya vestidas de luto» (versos 57-59) y el lexema «canallas» (verso 75). Las razones parecen obvias: el deliberadamente pretendido lenguaje popular y coloquial aparece en estos versos dominado por un temple prosaico que interrumpe el curso narrativo del poema; la violencia y soltura del discurso poético quedan truncadas por el ado-

ma de un gran poeta cuyo nombre la Redacción de EL MONO AZUL estima oportuno no dar por el momento" (El Mono Azul, núm. 5, jueves 24 de septiembre de 1936, pág. 3).

28 Para más detalles, cfr. Manuel Aznar Soler y Luis Mario Schneider (eds.), II Congreso Internacional de Escritores Antifascistas (1937). Volumen III. Ponencias, documentos y testimonios, Barcelona, Laia, 1979. 
cenado y chabacano término canallas (que sigue, además, separado por coma, al vocablo corazón: «Pero de cada crimen nacen balas / que os hallarán un día el sitio / del corazón, canallas»). En cuanto a las variantes - paso por alto las disparidades de los signos de puntuación entre las dos versiones, ya que resulta evidente que los cajistas de la improvisada imprenta de El Mono Azul no respetaron la puntuación original, por lo que los signos de interrogación e interjección aparecen también al principio de oración-, cabe señalar el cambio de patria por país (verso 77 de «Es así» y 74 de la versión definitiva), cambio muy dentro de la lógica poética nerudiana: por una parte trata de desindividualizar —o, mejor, de colectivizar - su yo poético; por la otra, si bien país puede ser sustituto de patria, sabido es que este término fue, a partir de la segunda mitad de la década de los treinta, de uso casi exclusivo de la derecha reaccionaria. Cabe también apuntar la variante del verso 23: «la luz dura de junio jugaba con tu pelo» se transforma en «la luz de junio ahogaba flores en tu boca». Se trata, en mi opinión, de una modificación debida a razones de coherencia de significado: el asesinato de García Lorca, que tanto había afectado, como hemos visto, a Neruda ${ }^{29}$, era un acto terrible: no podía aparecer emparejado con la acepción lúdica del verbo jugar. En el verso 51 constatamos otra variante significativa: el sintagma la calle cambia, en la versión última, de número, obedeciendo asimismo a razones de coherencia significacional: «Bandidos con aviones y con moros / [...] venían por el cielo a matar niños, / y por las calles la sangre de los niños / corría simplemente, como sangre de niños».

El cambio del título nos induce desde un principio a suponer que el poeta consideraba que la segunda versión se ajustaba más al contenido del poema. Esa suposición queda ampliamente confirmada si reparamos en que el título definitivo es, a la par que más explícito, más didáctico, pues explicar tiene, entre otros, y según el diccionario de la Real Academia, los significados siguientes: «[...] Exponer cualquiera materia, doctrina o texto difícil, por palabras muy claras con que se haga más perceptible; Dar a conocer la causa o motivo de alguna cosa». Se trataba, en definitiva - y Neruda se daba buena cuenta de ello- de explicar al lector las causas de su nueva poética, los motivos que habían deterfusilado; fue asesinado [...] La incidencia de aquel crimen fue para mí la más dolorosa de una larga lucha.» (Confieso que he vivido, op. cit., pág. 173). 
minado el cambio de su yo lírico: el testigo distanciado e indiferente de la Residencia en la tierra $I I^{30}$, hastiado incluso de sí mismo ${ }^{31}$, se ha convertido en el testigo acusador que denuncia los crímenes de los fascistas y que lucha implacablemente contra ellos. Ha habido, evidentemente, etapas intermedias ${ }^{32}$, pero la evolución ha sido tan axiomática y repentina que requiere explicaciones.

En efecto, el poema comienza de una manera insólita: con una pregunta a los lectores, a quienes considera sorprendidos $(0$, incluso, desconcertados) ante su nuevo estilo ${ }^{33}$, ante su opción por un nuevo credo estético-ideológico. De ahí la mención de las lilas, las amapolas y

30 Acaso cabe recordar que en este volumen abundan las formas verbales hay, sucede, etc.

31 Me limito a reproducir sólo algunos versos significativos de «Walking around»: «Sucede que me canso de ser hombre./ [...] Sucede que me canso de mis pies y mis uñas / y mi pelo y mi sombra./ Sucede que me canso de ser hombre» (I, pág. 219).

32 Me refiero principalmente a «Bruselas», «El abandonado» y «Reunión bajo las nuevas banderas». En el primer poema mencionado son patentes su deseo de salir de la incomunicación que le acosa (pensemos, por ejemplo, en estos versos de «Vals»: «Yo toco el odio como pecho diurno, / yo sin cesar, de ropa en ropa vengo / durmiendo lejos. // No soy, no sirvo, no conozco a nadie, / no tengo armas de mar ni de madera, / no vivo en esta casa.» I, pág. 259) y su leve pero perceptible gesto de ofrecimiento: «De todo lo que he hecho, de todo lo que he perdido, / de todo lo que he ganado sobresaltadamente, / en hierro amargo, en hojas, puedo ofrecer un poco» (I, pág. 260). En «El abandonado», la búsqueda del contacto y el intercambio es aún más explícita: "Yo no sé, yo sólo sufro de no saber quién eres / y de tener la sílaba guardada por tu boca, / [...] // Te busco, busco tu efigie entre las medallas / que el cielo gris modela y abandona, / no sé quién eres pero tanto te debo / que la tierra está llena de mi tesoro amargo./ [...] Qué hoja al caer no fue para mí un libro largo / de palabras por alguien dirigidas y amadas? / [...]// Eres, eres tal vez, el hombre o la mujer / o la ternura que no descifró nada.» (I, págs. 261-262). En «Reunión bajo las nuevas banderas» queda, en fin, claramente manifiesta la metamorfosis: «No, ya era tiempo, huid, / sombras de sangre, / hielos de estrella, retroceded al paso de los pasos humanos / y alejad de mis pies la negra sombra! // Yo de los hombres tengo la misma mano herida, / yo sostengo la misma copa roja / e igual asombro enfurecido: / un día / palpitante de sueños / humanos, un salvaje / cereal ha llegado / a mi devoradora noche / para que junte mis pasos de lobo / a los pasos del hombre. / Y así, reunido, / duramente central, no busco asilo / en los huecos del llanto: muestro / la cepa de la abeja: pan radiante / para el hijo del hombre: en el misterio el azul se prepara / para mirar un trigo lejano de la sangre./ [...] // Juntos, frente al sollozo! / Es la hora / alta de tierra y de perfume, mirad este rostro / recién salido de la sal terrible [...]» (I, págs. 270-271).

33 Si bien este poema aparece en el libro, precedido por otros, hemos de tener presente que éste era el primero del libro que publicaba firmado, y además, precisamente, en una revista destinada a los combatientes y editada, como sabemos, por la Alianza de Intelectuales Antifascistas. 
la lluvia de antaño, paradigmas notorios de una determinada simbología ${ }^{34}$ :

PREGUNTARÉIS: ¿Y dónde están las lilas?

¿Y la metafísica cubierta de amapolas?

¿Y la lluvia que a menudo golpeaba

sus palabras llenándolas

de agujeros y pájaros? ${ }^{35}$

Y después de los interrogantes de esta primera estrofa, un verso en solitario, que revela escuetamente y sin rodeos el talante narrativo de su nueva poesía, fruto de un acontecimiento histórico concreto: la guerra civil española y los criminales bombardeos de las tropas fascistas:

Os voy a contar todo lo que me pasa.

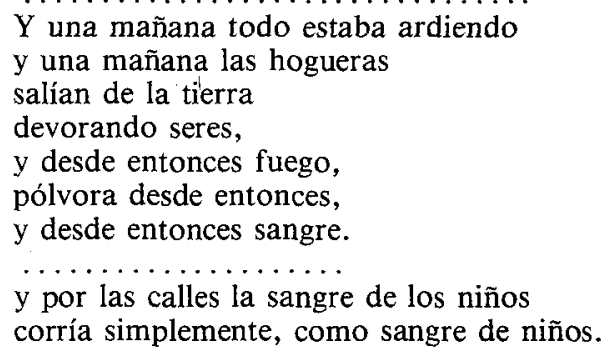

Renace el recuerdo de su casa del barrio de Argüelles, de sus amigos más queridos, de la ventura de los niños, del febril latido de la solícita, jovial y apiñada vida cotidiana de la colectividad, de los alimentos más indispensables y populares ${ }^{36}$.

Cfr. por ejemplo, «Galope muerto» (I, pág. 173), y el poema número 5 («Amiga, no te mueras») de El hondero entusiasta (I, pág. 163). En cuanto a la lluvia evocadora para Neruda de la infancia - cfr. «Infancia y poesía», en Confieso que he vivido, op. cit., pág. 15: «Comenzaré por decir, sobre los días y años de mi infancia, que mi único personaje inolvidable fue la lluvia. La gran lluvia austral que cae como una catarata del Polo, desde los cielos del Cabo de Hornos hasta la frontera. En esta frontera, o Far West de mi patria, nacía a la vida, a la tierra, a la poesía y a la lluvia. Por mucho que he caminado me parece que se ha perdido ese arte de llover que se ejercía como un poder terrible y sutil en mi Araucanía natal. Llovía meses enteros, años enteros». I, pág. 275.

«Yo vivía en un barrio / de Madrid, con campanas, / con relojes, con árboles. // Desde allí se veía / el rostro seco de Castilla / como un océano de cuero. / Mi casa era llamada / la casa de las flores, porque por todas partes / estallaban geranios: era / una bella casa / con perros y chiquillos. / Raúl, te acuerdas? / Te acuerdas, 
Y, frente a esa especie de concordia idealizada, la destrucción, la muerte, el terror, el odio de la guerra. Odio que queda claramente reflejado en las imprecaciones y en los insultos - he aquí otro de los elementos de la nueva etapa poética nerudiana- a los principales grupos que integraban el bando insurrecto ${ }^{37}$.

La penúltima estrofa vuelve al interrogante de la primera, pero ahora no va seguida de una explicación, sino de una exhortación: el dramatismo del momento histórico obligaba a los poetas a optar por una bandera:

Preguntaréis por qué su poesía
no nos habla del sueño, de las hojas,
de los grandes volcanes de su país nata
Venid a ver la sangre por las calles,
venid a ver
la sangre por las calles,
venid a ver la sangre
por las calles!

Desde el punto de vista formal cabe acaso recordar que varias de las figuras retóricas presentan el inconfundible cuño nerudiano de la etapa anterior: las comparaciones inesperadas ${ }^{38}$, las metáforas intrépidas y aplomadas ${ }^{34}$, las elipsis ${ }^{40}$, las enumeraciones, las anáforas, la presentación de lo inmaterial como lo material y lo genérico particula-

Rafael? / Federico, te acuerdas / debajo de la tierra, / te acuerdas de mi casa con balcones en donde / la luz de junio ahogaba flores en tu boca? / Hermano, hermano! / Todo / eran grandes voces, sal de mercaderías, / aglomeraciones de pan palpitante, / mercados de mi barrio de Argüelles con su estatua / como un tintero pálido entre las merluzas: / el aceite llegaba a las cucharas, / un profundo latido / de pies y manos llenaba las calles, / metros, litros, esencia / aguda de la vida, / pescados hacinados, / contextura de techos con sol frío en el cual / la flecha se fatiga, / delirante marfil fino de las patatas, / tomates repetidos hasta el mar» (versos 7-39).

«Bandidos con aviones y con moros,/ bandidos con sortijas y duquesas, / bandidos con frailes negros bendiciendo / venían por el cielo a matar niños) (versos 47-50); «Chacales que el chacal rechazaría, / piedras que el cardo seco mordería escupiendo, / víboras que las víboras odiaran!» (versos 53-55); «Generales / traidores: / mirad mi casa muerta, / mirad España rota: / pero de cada casa muerta sale metal ardiendo / en vez de flores, / pero de cada hueco de España / sale España, / pero de cada niño muerto sale un fusil con ojos,/ pero de cada crimen nacen balas / que os hallarán un día el sitio / del corazón» (versos 60-71).

Por ejemplo: «El rostro seco de Castilla / como un océano de cuero» (versos 11-12); «[...] con su estatua / como un tintero pálido entre las merluzas» (versos 28-29).

Cfr. los versos $4-5,15,24,27,37-38$, etc.

40 Verso 30 , por ejemplo. 
rizado ${ }^{41}$. Sin embargo, como bien apunta Alazraki, «ha desaparecido el procedimiento de membra disjecta para expresar su visión de desintegración de la realidad, ya no tiene lugar la presentación de lo comparativo a su fantasía y, en general, lo caótico de la imaginería tiende a un cierto orden y homogeneidad» ${ }^{42}$. Las enumeraciones están ahora caracterizadas por un lenguaje casi coloquial con el fin de acentuar el alcance poético de lo cotidiano. La excesivamente trabajada y trabajosa imaginería de antaño ha reducido notoriamente la altura de vuelo para que pueda ser percibida por las multitudes. La relación entre forma y contenido es ya más acorde. El subconsciente ha aminorado sus apariciones. Se percibe, en fin, un profundo humanismo, una incondicionada sed de justicia, un definitivo descuido de los propios sufrimientos y una cabal solidaridad con los padecimientos ajenos, una vivencia más directa de la realidad («Yo vivía en un barrio de Madrid [...]»). De ahí, por tanto, el nuevo acento épico de su poesía (que culminaría en Canto general), la deliberada naturalidad de su lenguaje poético (que culminaría en las Odas elementales) y la nueva distribución de las antítesis: flores, pan, pescado, aceite vs fuego, sangre, bandidos, chacales; generales y moros vs fusiles con ojos (o sea: milicianos).

\section{A modo de epílogo}

De lo dicho podemos deducir que la evolución estética de Neruda durante su estancia madrileña no respondía $-o$, menos aún, estaba supeditada- a una conversión ideológica, a una militancia estricta: Neruda no había asimilado aún, como convicción intelectual o de artículo de fe, los postulados del materialismo histórico, base incondicional de una militancia plena. Su nueva estética surgía de la terrible realidad del momento: como él mismo declara en la nota que antepone a «Las furias y las penas», su poesía ha cambiado porque el mundo ha cambiado. Por eso a su llegada a Santiago, en octubre de 1937, no vacila en afirmar, en unas declaraciones a Morales Álvarez:

Yo no soy comunista. Ni socialista. Ni nada. Soy, simplemente, escritor. Escritor libre, que ama la libertad con sencillez. Amo al pueblo. Pertenezco a

41 Jaime Alazraki, Poética y poesía de Pablo Neruda, New York, Las Américas Publishing Company, 1965, pág. 194.

42 Jaime Alazraki, Poética y poesía de Pablo Neruda, op. cit., pág. 194. 
él porque de él vengo. Por ello soy antifascista. Mi adhesión al pueblo no peca de ortodoxia ni de sometimiento ${ }^{43}$.

Cabe además señalar con insistencia que su amistad y continuado contacto con Alberti, González Tuñón, Serrano Plaja y Prados, comunistas convencidos desde antes del octubre rojo asturiano de 1934, tuvo una paulatina pero constante influencia en Neruda: influjo que se iba perfilando, como hemos visto, lentamente, en los poemas de las secciones I, II y III de la Tercera residencia. La sección IV, empero, no ofrece elementos que nos permitan afirmar, en contra de la opinión de varios críticos, que el poema «España pobre por culpa de los ricos» es un ejemplo evidente de su concepción marxista: la violencia, la grosería del lenguaje y las imprecaciones condicionan en buena medida los supuestos argumentos materialistas. El materialismo histórico es, como sabemos, ante todo, una concepción metacientífica de la historia, que atribuye a la economía un papel decisivo y esencial en el conocimiento histórico, y a lo económico una función análoga en el devenir histórico. El materialismo histórico es, pues, dialéctico, y no reductivo. Ni que decir tiene que «España pobre por culpa de los ricos» carece de elementos que confirmen tales afirmaciones ${ }^{44}$.

Hasta 1946 no surgen poemas que encarnen expresamente lo que podríamos llamar una «representación» de la lucha de clases. Me refiero, sobré todo ${ }^{45}$, a Las flores de Punitaqui, el libro XI de Canto ge-

43 Cfr. Raúl Morales Álvarez: «El arte de mañana será un quemante reportaje hecho de la actualidad», en Ercilla, núm. 132, vol. III, 1937. Citado por Jaime Alazraki, Poética y poesía de Pablo Neruda, op. cit., pág. 188.

44 «Malditos los que un dia / no miraron, malditos ciegos malditos, / los que no adelantaron a la solemne patria / el pan sino las lágrimas, malditos / uniformes manchados y sotanas / de agrios, hediondos perros de cueva y sepultura. / La pobreza era por España / como caballos llenos de humo, / como piedras caídas del / manantial de la desventura, / tierras cereales sin / abrir, bodegas secretas / de azul y estaño, ovarios, puertas, arcos / cerrados, profundidades / que querían parir, todo estaba guardado / por triangulares guardias con escopeta, / por curas de color de triste rata, / por lacayos del rey de inmenso culo. / España dura, país manzanar y pino, / te prohibían tus vagos señores: / A no sembrar, a no parir las minas, / a no montar las vacas, al ensimismamiento / de las tumbas, a visitar cada año / el monumento de Cristóbal el marinero, a relinchar / discursos con macacos venidos de América, / iguales en 'posición social' y podredumbre. / No levantéis escuelas, no hagáis crujir la cáscara / terrestre con arados, no llenéis los graneros / de abundancia trigal: rezad, bestias, rezad, / que un dios de culo inmenso como el culo del rey / os espera: Allí tomaréis sopa, hermanos míos» (I, págs. 273-274).

45 En los tercetos de «Salitre», el soneto aparecido en el diario santiaguino El Siglo, el 27 de diciembre de 1946, es también manifiesto el propósito de representar poéti- 
neral. España en el corazón es evidentemente un claro ejemplo de poesía civil, pero no de poesía militante o revolucionaria. No podía ser de otro modo, puesto que entonces Neruda, como hemos visto y según se trasluce con meridiana evidencia, de sus manifiestos de Caballo verde, su poesía sin pureza, además de carecer de un programa poético concreto y coherente, excluía, precisamente, la poesía militante o revolucionaria. $Y$ eso pese a su amistad y trato diario con Alberti, que, desde hacía años, tenía - y la defendía abiertamente - una concepción marxista de la cultura, y que había fundado, en junio de 1933, la revista Octubre, que llevaba, además, justamente, un subtítulo muy explícito (Escritores y artistas revolucionarios) y, al final de cada número, el colofón siguiente:

\section{POR UNA LITERATURA PROLETARIA}

Camaradas obreros y campesinos: la revista OCTUBRE no es una revista de minorías. Es un revista para vosotros. Debéis tomar parte en ella, enviándonos vuestras impresiones del campo y de la fábrica, críticas, biografías, artículos de lucha, dibujos. La cultura burguesa agoniza, incapaz de crear nuevos valores, los únicos herederos legítimos de toda la ciencia, la literatura y el arte que han ido acumulando los siglos, son los obreros y campesinos, la clase trabajadora, que, como dice Carlos Marx, es la que lleva en sí el porvenir.

Así se explica que en sus memorias Neruda no mencione ni una sola vez a sus coetáneos -y por él bien conocidos escritores madrileños (los más no lo eran de nacimiento, pero vivían y trabajaban en Madrid desde hacía tiempo) - de la nueva novela de avanzada o revolucionaria ${ }^{46}$ : César M. Arconada, Ramón J. Sender, José Díaz Fernández, Joaquín Arderíus, José Antonio Balbontín, César Falcón ${ }^{47}$ y Andrés

camente la lucha de clases: «Junto a tu nívea luz de estalactita, / duelo, viento y dolor, el hombre habita: / harapo y soledad son su medalla. // Hermanos de las tierras desoladas: / aquí tenéis como un montón de espadas / mi corazón dispuesto a la batalla» (II, pág. 1064).

46 Quizá no está de más recordar en este contexto que, entre las varias colecciones de novelas cortas y relatos de manifiesta intencionalidad revolucionaria, había algunas con nombres muy explícitos. Por ejemplo, La Novela Proletaria (Madrid, 1932-1933) y La Novela Roja (Madrid, 1931).

47 Falcón, peruano naturalizado español (estuvo casado con Irene Falcón, la secretaria de Dolores Ibárruri), es un escritor casi olvidado. Entre sus numerosas actividades culturales, destacan la fundación, con Mariátegui, del diario La Razón (1918), que dejó de existir tres meses después, tras negarse el impresor a publicarlo por miedo a represalias gubernamentales. A raíz de esto, el gobierno les nombró Propagandistas del Perú en el Extranjero. Mariátegui residirá en Italia, Falcón en España. En Madrid, Falcón colaboró en El Liberal, y, después, en El Sol, en calidad de re- 
Carranque de Ríos. Pero sabido es que Neruda silencia en Confieso que he vivido muchos nombres ${ }^{48}$.

dactor. En diciembre de 1923, la dirección le nombró corresponsal en Londres, cargo que desempeñó hasta 1929. En 1930 funda el semanario político-cultural Nosotros, que fue, con Nueva España (1930-1931), una de las principales revistas de la época y portavoz oficial de la Izquierda Revolucionaria Anti-Imperialista, el partido que fundó Falcón en ese mismo año. Ni que decir tiene que Nosotros -que tuvo tiradas muy altas - fue objeto de continuas agresiones por parte de los primeros grupúsculos fascistas que entonces pululaban por Madrid. Con la llegada de la República, Falcón regresó a Madrid y volvió a colaborar en los semanarios de izquierdas (sobre todo en Nosotros y Pueblo). Con su esposa creó, en 1932, el grupo de teatro proletario de agitación Nosotros, con sede y local de representaciones en la Calle de Alcalá. En 1933 fue elegido diputado por Málaga. En 1934 fundó, en Sevilla, el diario Verdad. En enero de 1936, cuando reapareció legalmente Mundo Obrero, fue nombrado director. Durante la guerra civil organizó Altavoz del frente y Frente Rojo, órgano central del P.C.E. Es, pues, sorprendente, que Neruda no mencione a Falcón en sus memorias.

Ese es el caso, a título de ejemplo, del conde y filósofo báltico Hermann Keyserling, recientemente recordado, en lúcido y polémico ensayo, por Rafael Gutiérrez Girardot: «El Conde se fascinó con el ser mineraloide de Latinoamérica y, posiblemente, a esa intuición se deben tantas estrofas minerales de Neruda, quien conoció al Conde en Madrid, aunque en sus Memorias lo calla, como muchas otras cosas más.» En «Cómo se lee la literatura latinoamericana en Europa», Camp del arpa, núm. 55-56 (octubre de 1978), pág. 62. 